13.2; $13.3 ; 13.4$

\title{
Влияние микропримесей $d$-элементов на электронную структуру кристаллитов оксида бария в катодах СВЧ-приборов
}

\author{
() В.И. Капустин ${ }^{1}$, И.П. Лй ${ }^{2}$ А.В. Шуманов ${ }^{1,2}$, С.О. Москаленко ${ }^{1,2}$, Р.P. Залялиев ${ }^{1}$, Н.Е. Кожевникова ${ }^{2}$ \\ ${ }^{1}$ МИРЭА - Российский технологический университет, Москва, Россия \\ ${ }^{2} \mathrm{AO}$ „Плутон“, Москва, Россия \\ E-mail: kapustin@mirea.ru
}

Поступило в Редакцию 15 августа 2019г.

В окончательной редакции 15 августа 2019г.

Принято к публикации 28 октября 2019г.

\begin{abstract}
С использованием метода электронной спектроскопии для химического анализа впервые экспериментально установлено, что микропримеси $d$-элементов ( $\mathrm{W}, \mathrm{Re}, \mathrm{Ni}, \mathrm{Pd}, \mathrm{Os}$ ) в кристаллитах $\mathrm{BaO}$ из состава катодов СВЧ-приборов приводят к формированию на поверхности кристаллитов поверхностных состояний донорного типа, которые могут частично компенсировать поверхностные состояния акцепторного типа, обусловленные поверхностными кислородными вакансиями, что приводит к снижению потенциального барьера на поверхности кристаллитов и соответственно к снижению величины работы выхода катода.
\end{abstract}

Ключевые слова: катоды СВЧ-приборов, кристаллиты оксида бария, микропримеси $d$-элементов, поверхностные состояния донорного и акцепторного типа.

DOI: 10.21883/PJTF.2020.03.48983.18014

Основным эмиссионно-активным компонентом большинства материалов катодов СВЧ-приборов являются кристаллиты $\mathrm{BaO}$, которые формируются в материале на этапе изготовления и термического активирования катода. Эмиссионные свойства чистых кристаллитов $\mathrm{BaO}$ определяются кислородными вакансиями, формирующими на поверхности оксида поверхностные состояния акцепторного типа, которые приводят к искривлению энергетических зон у поверхности оксида вверх [1]. При этом в различных типах катодов концентрация вакансий в кристаллитах $\mathrm{BaO}$ после изготовления катода лежит в интервале $(2-6) \cdot 10^{25} \mathrm{~m}^{-3}$ и достигает величины $(3-5) \cdot 10^{26} \mathrm{~m}^{-3}$ после активирования катода [2,3]. В то же время распространенной является концепция, согласно которой на поверхности кристаллитов $\mathrm{BaO}$ имеет место адсорбция электроположительных атомов (бария, кальция, стронция), формирующих поверхностные состояния донорного типа, что приводит к искривлению энергетических зон оксида вниз [4].

Другим компонентом материалов катодов является металлическая фаза, в качестве которой используются $\mathrm{Ni}$ (оксидно-никелевые катоды), W (металлопористые и скандатные катоды), Pd (палладий-бариевые катоды), а также Re или Os, которые применяются в некоторых типах катодов в качестве пленочных покрытий, снижающих работу выхода и повышающих долговечность катодов. Традиционно считается [1,5], что тремя основными функциями металлической фазы катода являются инициирование разложения карбонатов или алюминатов бария, используемых в качестве компонентов при изготовлении катодов, с выделением кристаллитов $\mathrm{BaO}$; формирование в кристаллитах оптимальной концентрации кислородных вакансий; обеспечение необходимой электропроводности и теплопроводности материала катода.

При формировании электронной структуры многокомпонентных материалов основными факторами, определяющими характер этой структуры, являются валентный, размерный и электронный. Поэтому задача настоящей работы состоит в исследовании влияния указанных факторов на характер искривления энергетических зон у поверхности кристаллитов оксида бария.

Двойные диаграммы состояния $\mathrm{BaO}$, а также оксидов $\mathrm{Ca}, \mathrm{Al}, \mathrm{Sc}, \mathrm{W}, \mathrm{Re}, \mathrm{Os}, \mathrm{Pd}, \mathrm{Ni}$ имеют эвтектический характер, в них отсутствуют области взаимной растворимости оксидов, хотя нулевой взаимной растворимости компонентов не бывает в принципе. Действительно, в работах [2,6] методами оптической спектроскопии и электронной спектроскопии для химического анализа (ЭСХА) было показано влияние микропримесей $\mathrm{Ca}, \mathrm{Al}$, $\mathrm{Sc}$, а также синергетический эффект влияния микропримесей $\mathrm{Ca}$ и $\mathrm{Sr}$ (микропримесей $s$ - и $p$-элементов) на электронную структуру кристаллитов $\mathrm{BaO}$, а также на возможное появление пространственного упорядочения кислородных вакансий в кристаллитах $\mathrm{BaO}$. Показано влияние микропримесей $\mathrm{Ni}$ (валентность $+2.1-2.2$ ) и $\mathrm{Sc}($ валентность +3$)$, ионный радиус которых составляет 0.54 и 0.60 от ионного радиуса Ва, на сдвиг валентной зоны кристаллитов $\mathrm{BaO}$ и упорядочение кислородных вакансий в объеме кристаллитов. Данные исследования фактически позволили выявить влияние валентного и размерного факторов микропримесей на электронную структуру $\mathrm{BaO}$.

Такие компоненты катодных материалов, как $\mathrm{Ni}, \mathrm{W}$, $\mathrm{Re}, \mathrm{Pd}, \mathrm{Os}$, являются типичными $d$-элементами с узкой $d$-зоной, расположенной на расстоянии $E_{B}=0.0-6.0 \mathrm{eV}$ 


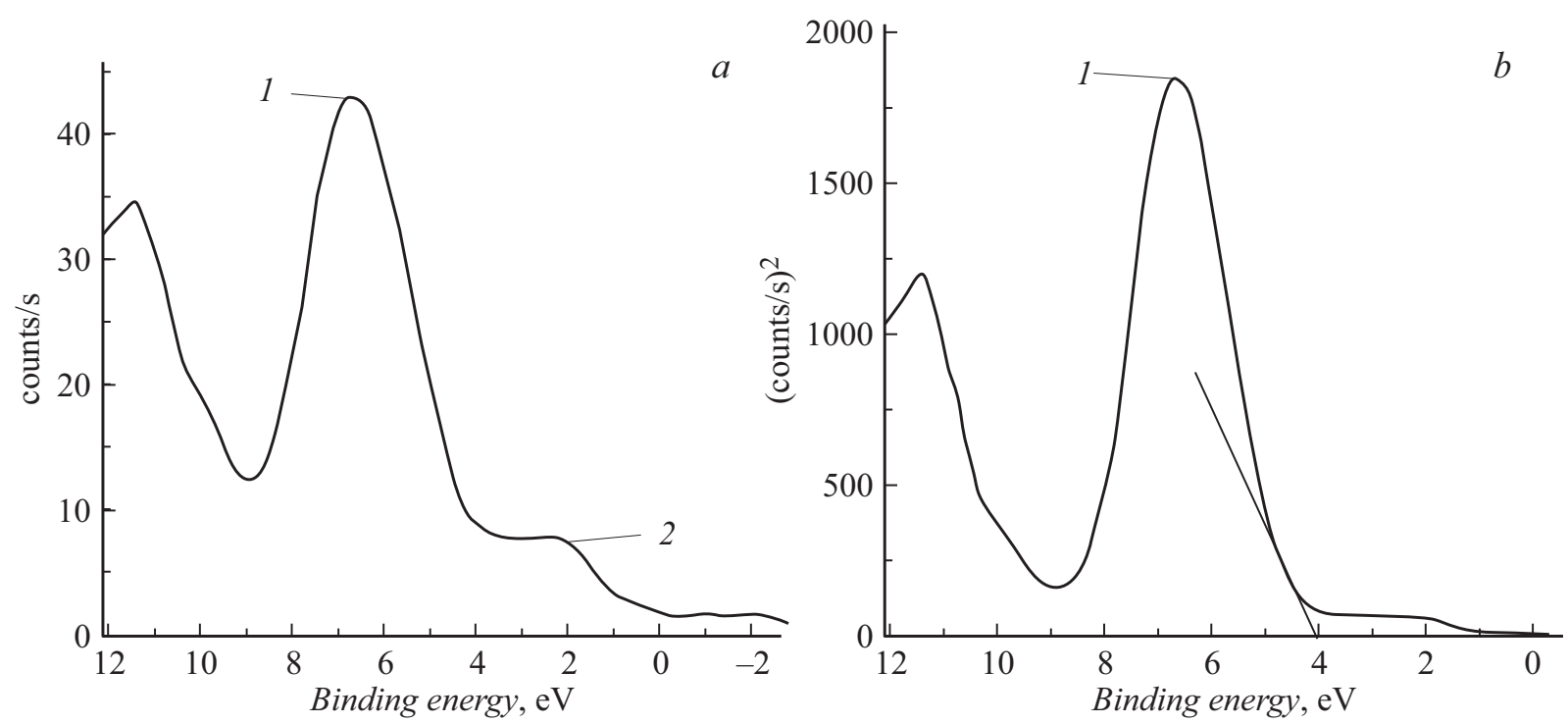

Рис. 1. Электронные спектры валентной зоны образца $\mathrm{BaO}+10$ wt.\% Ni(nano). Пояснение в тексте.

относительно уровня Ферми соответствующего металла, что соизмеримо с шириной запрещенной зоны кристаллитов ВаО. Поэтому можно ожидать, что при легировании кристаллитов $\mathrm{BaO}$ микропримесями $d$-элементов может проявиться третий - электронный - фактор влияния микропримесей на электронную структуру кристаллитов $\mathrm{BaO}$.

Образцы материалов были получены прессованием таблеток диаметром $7.6 \mathrm{~mm}$ и толщиной $1 \mathrm{~mm}$ из порошка карбоната бария (средний размер частиц $5 \mu \mathrm{m}$ ) и порошков $\mathrm{Pd}, \mathrm{Os}, \operatorname{Re}($ размер частиц 10-20 $\mu \mathrm{m}), \mathrm{W}$ (размер частиц 2-5 $\mu \mathrm{m}$ ), наноразмерного порошка $\mathrm{Ni}$ (средний размер частиц $80 \mathrm{~nm}$ ), порошка $\mathrm{Ni}$ (размер частиц 10-20 $\mu \mathrm{m})$ с последующим спеканием в вакууме при температуре $1200^{\circ} \mathrm{C}$ в течение $2 \mathrm{~h}$. В результате в материалах формировались кристаллиты $\mathrm{BaO}$, легированные другими компонентами в пределах их максимально возможной растворимости. Электронная структура валентной зоны образцов исследовалась с использованием спектрометра Theta Probe фирмы Thermo Scientific методом ЭСХА, шаг развертки спектров $0.05 \mathrm{eV}$. Обработка результатов проводилась с использованием методик, описанных в работе [2].

На рис. 1, $a$ приведены электронные спектры валентной зоны образца материала на основе карбоната бария, содержащего $10 \mathrm{wt} . \%$ нанопорошка Ni. Пик 1 относится собственно к валентной зоне $\mathrm{BaO}$, пик $2-$ к зоне проводимости частиц порошка $\mathrm{Ni}$. Поскольку плотность состояний у края валентной зоны оксида приближенно равна

$$
N_{V}(E) \propto \sqrt{\left|E_{V S}-E\right|}
$$

(где $E_{V S}$ - положение верха валентной зоны на поверхности оксида), на рис. $1, b$ представлен электронный спектр в координатах энергия связи-квадрат интенсив- ности. Прямая, проведенная у правого края пика 1 , позволяет определить величину $E_{V S}$.

На рис. 2 показаны электронные спектры валентной зоны $\mathrm{BaO}$, содержащего микропримеси Os $(a), \mathrm{Pd}(b)$ и $\operatorname{Re}(c)$, в координатах энергия связи-квадрат интенсивности, позволяющие определить параметр $E_{V S}$ для $\mathrm{BaO}$ с указанными микропримесями.

В таблице приведены значения величины $\left(E_{F}-E_{V S}\right)$ для $\mathrm{BaO}$, легированного микропримесями при совместном спекании порошка карбоната бария с порошками Os, $\mathrm{Pd}, \operatorname{Re}(10-20 \mu \mathrm{m})$, нанопорошком Ni $(80 \mathrm{~nm})$, а также некоторые параметры легирующих элементов: число $d$-электронов в атомах, энергия связи $d$-электронов $E_{B}$ в чистых металлах, максимальная валентность элемента, ионный радиус элемента $R_{i}$ относительно ионного радиуса бария $R_{\mathrm{Ba}}$. Для сравнения в таблице приведены также указанные параметры для образцов, полученных спеканием с порошком W $(2-5 \mu \mathrm{m})$, порошком $\mathrm{Ni}(10-20 \mu \mathrm{m})$, порошком карбоната кальция $(5 \mu \mathrm{m})$, взятые из работ $[2,6]$.

На рис. 3 приведена модель электронной структуры оксида бария, содержащего кислородные вакансии и микропримеси $d$-элементов. На рисунке использованы следующие обозначения: $E_{C}, E_{D}, E_{V}-$ положение низа зоны проводимости, уровня кислородных вакансий и верха валентной зоны в объеме; $E_{\mathrm{F}}-$ уровень Ферми; 1 - плотность состояний уровня вакансий в объеме, который расщепляется на две подзоны из-за их неупорядоченного расположения в кристаллитах [6]; 2 - плотность акцепторных состояний на поверхности, обусловленная поверхностными кислородными вакансиями; 3 и 4 - плотность собственных поверхностных состояний оксида; 5 - плотность донорных поверхностных состояний, обусловленных микропримесями $d$-элементов на поверхности; $E_{C S}, E_{V S}, E_{D S}, E_{A}-$ положения уровней 

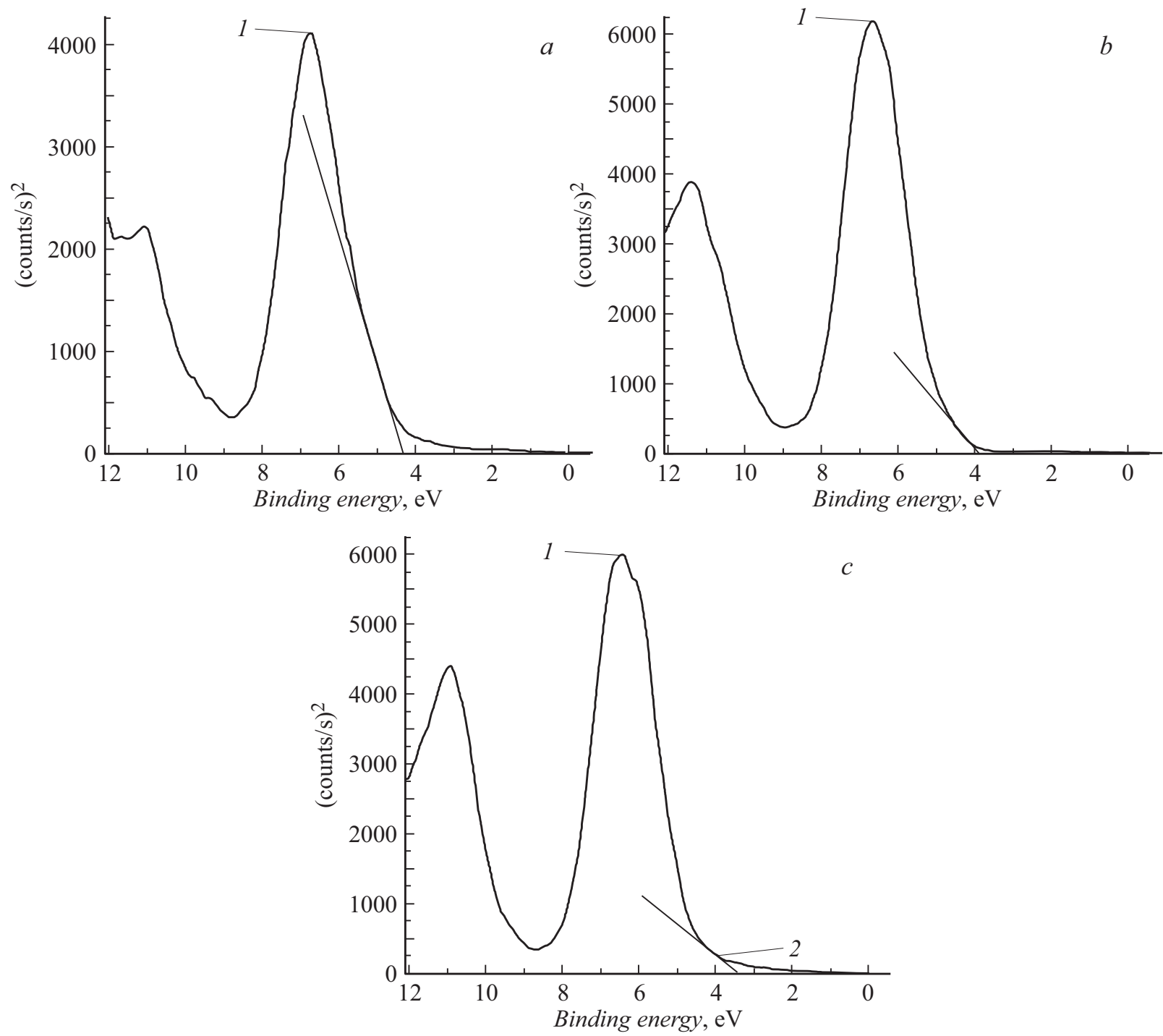

Рис. 2. Электронные спектры валентной зоны $\mathrm{BaO}$ с микропримесями $\mathrm{Os}(a), \mathrm{Pd}(b)$ и $\operatorname{Re}(c)$ в координатах энергия связи-квадрат интенсивности.

и состояний на поверхности. Отметим, что $E_{B} \neq E_{A}$, но, очевидно, $E_{A} \propto E_{B}$.

Величина работы выхода $\varphi$ оксида с широкой запрещенной зоной равна

$$
\varphi=\chi+\psi+V
$$

где $\chi=0.80 \mathrm{eV}-$ электронное сродство $\mathrm{BaO}$, $V=\left(E_{C}-E_{C S}\right)$ - величина искривления зон у поверхности оксида, $\psi$ - внутренняя работа выхода, равная

$$
\psi=\frac{\Delta E_{g}}{2}+k T \ln \left[\frac{2\left(2 \pi m^{*} k T\right)^{3 / 2}}{N_{D} h^{3}}\right]^{1 / 2} .
$$

В соотношении (3) $h$ - постоянная Планка, $m^{*}-$ эффективная масса электрона, $T$ - температура, $k-$ постоянная Больцмана, $\Delta E_{g}=\left(E_{C}-E_{D}\right), N_{D}-$ концентрация кислородных вакансий в объеме оксида. Поскольку ширина запрещенной зоны оксида бария равна $\left(E_{C}-E_{V}\right)=4.71 \mathrm{eV}[2]$, при концентрации вакансий
$N_{D}=(2-6) \cdot 10^{25} \mathrm{~m}^{-3}$, т. е. после изготовления катода, но до его активирования, и комнатной температуре $T=300 \mathrm{~K}$ величина

$$
\left(E_{\mathrm{F}}-E_{V}\right)=\left(E_{C}-E_{V}\right)-\psi=4.03 \mathrm{eV}
$$

в объеме оксида в соответствии с выражением (3). С учетом величины $\left(E_{\mathrm{F}}-E_{V S}\right)$, приведенной в таблице для различных легирующих примесей, для некоторых микропримесей в $\mathrm{BaO}$ при комнатной температуре имеет место изгиб зон у поверхности вверх, а для некоторых микропримесей - изгиб зон вниз, как указано в таблице. Отметим, что с ростом концентрации кислородных вакансий, т.е. при активировании катода, и с ростом температуры величина $\psi$ в соответствии с (3) уменьшается, а величина $\left(E_{\mathrm{F}}-E_{V}\right)$ растет.

Полученные экспериментальные результаты с учетом данных таблицы и модели, приведенной на рис. 3, позволяют сформулировать следующий механизм влияния 
Положение края валентной зоны относительно уровня Ферми оксида бария, легированного микропримесями $d$-элементов

\begin{tabular}{|c|c|c|c|c|c|c|c|c|}
\hline \multirow{2}{*}{ Параметр } & \multirow{2}{*}{$\begin{array}{c}\text { Чистый } \\
\mathrm{BaO}\end{array}$} & \multicolumn{7}{|c|}{ Легирующие элементы } \\
\hline & & $\mathrm{Ca}$ & $\mathrm{W}$ & $\operatorname{Re}$ & & & $\mathrm{Pd}$ & Os \\
\hline $\begin{array}{c}\text { Размер частиц } \\
\text { порошка }\end{array}$ & $5 \mu \mathrm{m}$ & $5 \mu \mathrm{m}$ & $2-5 \mu \mathrm{m}$ & $10-20 \mu \mathrm{m}$ & $10-20 \mu \mathrm{r}$ & $80 \mathrm{~nm}$ & $10-20 \mu \mathrm{m}$ & $10-20 \mu \mathrm{m}$ \\
\hline $\begin{array}{c}\text { Число } \\
d \text {-электронов }\end{array}$ & - & - & 4 & 5 & \multicolumn{2}{|c|}{8} & 10 & 6 \\
\hline $\begin{array}{c}E_{B}, \mathrm{eV} \\
\text { (в металле) }\end{array}$ & - & - & 6.0 & 4.0 & \multicolumn{2}{|c|}{4.0} & 1.0 & \\
\hline $\begin{array}{c}\text { Максимальная } \\
\text { валентность }\end{array}$ & +2 & +2 & +6 & +7 & \multicolumn{2}{|c|}{$+2.1-2.2$} & +4 & +8 \\
\hline$R_{i} / R_{\mathrm{Ba}}$ & 1.0 & 0.76 & 0.48 & 0.38 & \multicolumn{2}{|c|}{0.54} & 0.47 & 0.48 \\
\hline$\left(E_{\mathrm{F}}-E_{V S}\right), \mathrm{eV}$ & 2.70 & 2.75 & 3.05 & 3.45 & 3.18 & 4.03 & 3.83 & 4.30 \\
\hline $\begin{array}{c}\text { Направление } \\
\text { искривления зон } \\
\text { у поверхности }\end{array}$ & \multicolumn{6}{|c|}{ Вверх } & Bверх & Вниз \\
\hline
\end{tabular}

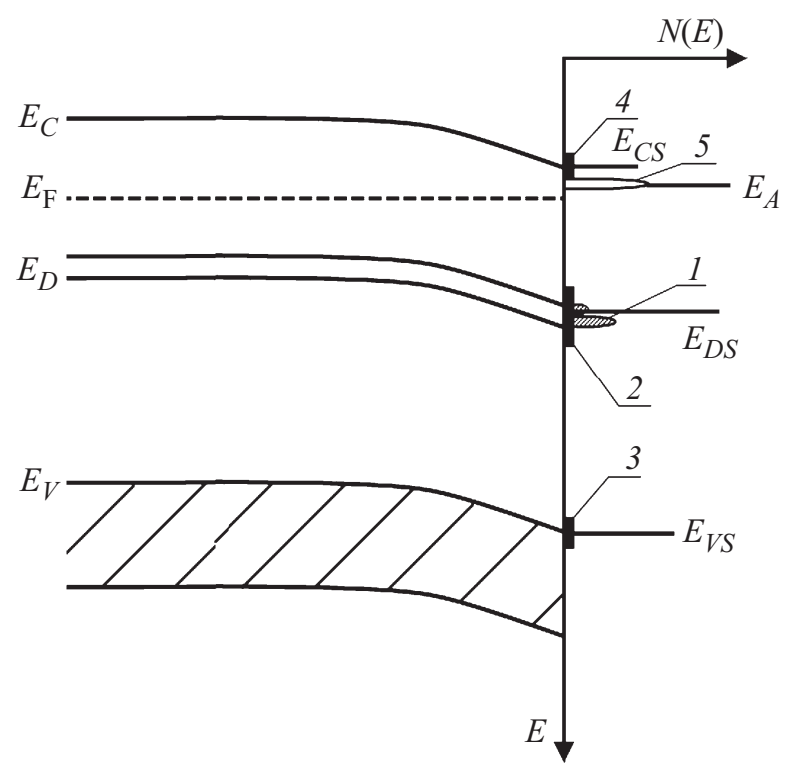

Рис. 3. Модель электронной структуры оксида бария, содержащего кислородные вакансии и микропримеси $d$-элементов. Пояснение в тексте.

микропримесей $d$-элементов на электронную структуру кристаллитов $\mathrm{BaO}$ из состава катодов СВЧ-приборов.

1. Кислородные вакансии в чистом $\mathrm{BaO}$ формируют на поверхности кристаллитов $\mathrm{BaO}$ поверхностные состояния акцепторного типа, которые приводят к изгибу электронных зон у поверхности оксида вверх.

2. Микропримеси $d$-элементов в кристаллитах $\mathrm{BaO}$, валентность которых больше +2 , формируют на поверхности кристаллитов поверхностные состояния донорного типа. В зависимости от положения энергии этих донорных состояний относительно положения акцепторных состояний кислородных вакансий, а также от величины поверхностной плотности $d$-элементов и поверхностной плотности кислородных вакансий акцепторные состояния могут заполняться электронами с указанных поверхностных донорных состояний, а не с состояний в объеме оксида. Это может привести к изменению величины и знака поверхностного заряда оксида, т.е. к изменению величины и направления искривления зон у поверхности оксида и соответственно к изменению его работы выхода. Данный эффект наглядно проявляется при легировании кристаллитов оксида бария осмием.

3. Использование нанопорошка $d$-элемента для легирования кристаллитов оксида бария позволяет эффективно повысить поверхностную плотность $d$-элементов в кристаллитах $\mathrm{BaO}$.

\section{Конфликт интересов}

Авторы заявляют, что у них нет конфликта интересов.

\section{Список литературы}

[1] Капустин В.И. // Перспективные материалы. 2000. № 2. C. 5-17.

[2] Капустин В.И., Ли И.П., Шуманов А.В., Лебединский Ю.Ю., Заблоцкий А.В. // ЖТФ. 2017. Т. 87. В. 1. C. $105-115$.

[3] Капустин В.И., Ли И.П., Шуманов А.В., Москаленко С.О., Буш А.А., Лебединский Ю.Ю. // ЖТФ. 2019. Т. 89. В. 5. C. $771-780$.

[4] Свешников В.К., Базаркин А.Ф. // Электронная техника. Сер. 1. СВЧ-техника. 2014. В. 1(520). С. 70-75.

[5] Дюбуа Б.Ч., Королев А.Н. // Электронная техника. Сер. 1. СВЧ-техника. 2011. Вып. 1(509). С. 5-25.

[6] Капустин В.И., Ли И.П., Петров В.С., Леденщова Н.Е., Турбина А.В. // Электронная техника. Сер. 1. СВЧ-техника. 2016. B. 1(528). C. $8-18$. 